\title{
ARTICLE \\ Epidemiology \\ Family history of cancer, Ashkenazi Jewish ancestry, and pancreatic cancer risk
}

\author{
Tsuyoshi Hamada ${ }^{1}$, Chen Yuan ${ }^{2,3}$, Matthew B. Yurgelun ${ }^{2}$, Kimberly Perez ${ }^{2}$, Natalia Khalaf ${ }^{4}$, Vicente Morales-Oyarvide ${ }^{2}$, Ana Babic ${ }^{2}$,

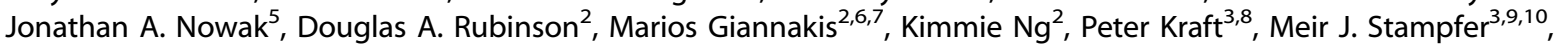 \\ Edward L. Giovannucci ${ }^{3,9,10}$, Charles S. Fuchs ${ }^{11,12,13}$, Shuji Ogino ${ }^{1,3,5,6}$ and Brian M. Wolpin ${ }^{2}$
}

BACKGROUND: Individuals with a family history of cancer may be at increased risk of pancreatic cancer. Ashkenazi Jewish (AJ) individuals carry increased risk for pancreatic cancer and other cancer types.

METHODS: We examined the association between family history of cancer, AJ heritage, and incident pancreatic cancer in 49410 male participants of the prospective Health Professionals Follow-up Study. Hazard ratios (HRs) were estimated using multivariableadjusted Cox proportional hazards models.

RESULTS: During 1.1 million person-years (1986-2016), 452 participants developed pancreatic cancer. Increased risk of pancreatic cancer was observed in individuals with a family history of pancreatic (HR, 2.79; 95\% confidence interval [Cl], 1.28-6.07) or breast cancer ( $\mathrm{HR}, 1.40 ; 95 \% \mathrm{Cl}, 1.01-1.94)$. There was a trend towards higher risk of pancreatic cancer in relation to a family history of colorectal cancer $(\mathrm{HR}, 1.21 ; 95 \% \mathrm{Cl}, 0.95-1.55)$ or $\mathrm{AJ}$ heritage $(\mathrm{HR}, 1.29 ; 95 \% \mathrm{Cl}, 0.94-1.77)$. The risk was highly elevated among AJ men with a family history of breast or colorectal cancer (HR, 2.61 [95\% Cl, 1.41-4.82] and 1.92 [95\% Cl, 1.05-3.49], respectively). CONCLUSION: Family history of pancreatic cancer was associated with increased risk of this malignancy. Family history of breast or colorectal cancer was associated with the increased risk among AJ men.

British Journal of Cancer (2019) 120:848-854; https://doi.org/10.1038/s41416-019-0426-5

\section{BACKGROUND}

Pancreatic cancer is the third leading cause of cancer-related mortality in the United States (U.S.) with an overall 5-year survival rate of $<10 \% .^{1}$ This high mortality rate is largely related to the diagnosis of patients at advanced stages when the disease is unresectable and thus incurable. ${ }^{2}$ Therefore, there is a great need for identification of risk factors for pancreatic cancer and establishment of screening strategies to reduce mortality associated with this malignancy.

Individuals with a family history of pancreatic cancer carry increased risks of pancreatic cancer ${ }^{3-8}$ and other cancer types..$^{9-11}$ In addition to environmental and lifestyle factors shared by family members, studies have identified genes that contribute to familial clustering of pancreatic cancer, including ATM, BRCA1, BRCA2, CDKN2A, and PALB2, as well as PRSS1 and SPINK1 for hereditary pancreatitis. ${ }^{12-18}$ Evidence also links family history of other cancer types to increased risk of pancreatic cancer. ${ }^{5-8,18,19} B R C A 1$ and $B R C A 2$ for hereditary breast and ovarian cancer, DNA mismatch repair genes responsible for Lynch syndrome, and CDKN2A for familial atypical multiple melanoma and mole syndrome may contain underlying germline mutations that predispose to pancreatic cancer and other cancer types. ${ }^{16-23}$ However, the association of family history of various cancer types with risk of pancreatic cancer has not been fully evaluated in prospective studies with long duration of follow-up. Furthermore, individuals of Ashkenazi Jewish (AJ) heritage represent a genetically distinct population, ${ }^{24-27}$ which is characterised by higher prevalence of germline mutations in BRCA1, BRCA2, MSH2, and $\mathrm{MSH}^{28-30}$ and higher incidence of various malignancies including pancreatic cancer. $^{31-35}$ The National Comprehensive Cancer Network (NCCN) guidelines recommend genetic counselling for $A J$ individuals diagnosed with pancreatic cancer. ${ }^{36}$ Yet, the association of family

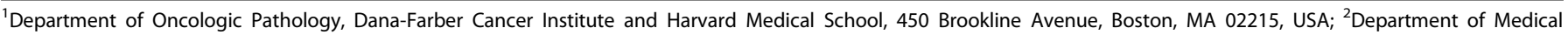

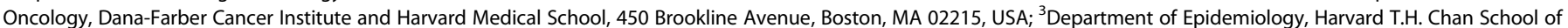

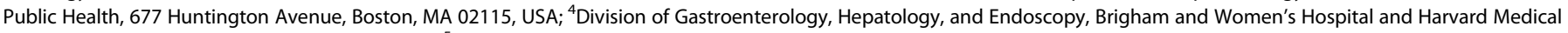

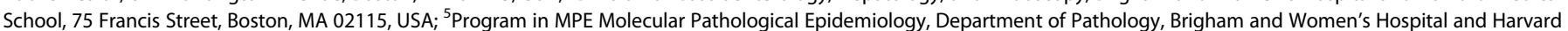

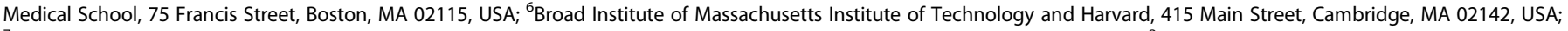

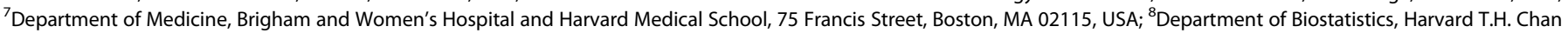

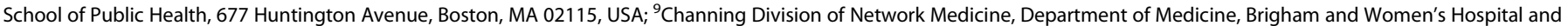

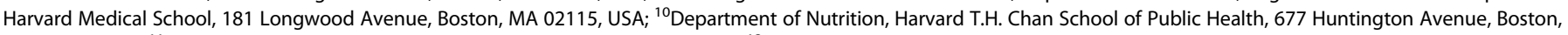

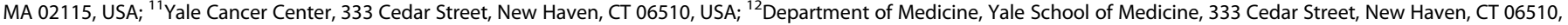
USA and ${ }^{13}$ Smilow Cancer Hospital, 20 York Street, New Haven, CT 06519, USA

Correspondence: Brian M. Wolpin (bwolpin@partners.org)

These authors contributed equally: Tsuyoshi Hamada, Chen Yuan.

These authors jointly supervised this work: Shuji Ogino, Brian M. Wolpin.

Received: 13 November 2018 Revised: 25 February 2019 Accepted: 27 February 2019

Published online: 14 March 2019 
history with risk of pancreatic cancer is not well defined in the context of religious heritage.

To test the hypothesis that family history of other cancer types is associated with increased risk of pancreatic cancer, we conducted a prospective study based on a large U.S. cohort. We further examined pancreatic cancer risk associated with cancer family history by AJ ancestry.

\section{MATERIALS AND METHODS}

Study population

We collected data from an ongoing prospective cohort study in the U.S., the Health Professionals Follow-up Study (HPFS). ${ }^{37}$ In 1986, the HPFS cohort was established when 51,529 male health professionals aged 40-75 years (dentists, optometrists, osteopaths, pharmacists, podiatrists, and veterinarians) returned a baseline questionnaire. Participants have been sent questionnaires to report demographics, medical and social history, and health outcomes such as cancer diagnoses every 2 years, and to report dietary patterns every 4 years. Participants were followed until diagnosis of pancreatic adenocarcinoma, death from any cause, or the end of follow-up (31 January 2016), whichever came first. The follow-up rate has been more than $90 \%$ for each follow-up questionnaire cycle. Informed consent was obtained from all participants at study enrolment, and the HPFS was approved by the institutional review board at Harvard T.H. Chan School of Public Health (Boston, MA, USA).

Patients with pancreatic cancer were identified by self-report, next-of-kin, or review of the National Death Index. Physicians blinded to exposure data confirmed the diagnosis of pancreatic adenocarcinoma by review of medical records, death certificates, or cancer registry data. Deaths were ascertained based on information from next of kin, U.S. postal service, and/or the National Death Index; this method has been shown to capture $>98 \%$ of deaths. ${ }^{38}$ We excluded participants with a history of cancer at baseline (exception of non-melanoma skin cancer) and those without available data on family history of cancer.

\section{Assessment of family history of cancer}

We utilised data on family history of cancer in first-degree relatives including parents, siblings, and offspring which have been prospectively collected from questionnaires. Family history was assessed in 1996 for breast cancer; in 1986, 1990, 1992, 1996, 2008, and 2012 for colorectal cancer; in 2008 for pancreatic cancer; in 1990, 1992, and 2008 for melanoma; in 1990, 1992, and 1996 for prostate cancer; and in 1992 for lung cancer. A positive family history for each cancer type was defined when the participant reported any first-degree relative diagnosed with the corresponding cancer. Participants were treated as those with a family history of a specific cancer type from the first report of a first-degree relative diagnosed with the cancer. Follow-up time for the analysis of each cancer type started at the first year when a family history of the cancer was assessed.

\section{Ascertainment of covariates}

In the questionnaire from 1998, participants were asked their religious heritage (Ashkenazi Jewish, Sephardic Jewish, Catholic, Protestant, other Christian, Eastern, Muslim, or other). For analyses adjusted for or stratified by AJ ancestry, follow-up time started from 1998. Data on other covariates were collected at baseline in 1986 and in follow-up questionnaires, including age, race, smoking status, diabetes mellitus, body mass index (BMI), physical activity level, alcohol intake, and regular multivitamin use.

\section{Statistical analysis}

Using the Cox proportional hazards regression model, we examined the association between family history of each cancer type and risk of pancreatic cancer, and estimated hazard ratios
(HRs) of pancreatic cancer incidence and $95 \%$ confidence intervals (Cls). The multivariable Cox regression models were adjusted for the following potential confounders including known risk factors for pancreatic cancer: ${ }^{2,39}$ age (continuous), race (white, black, other, or unknown), calendar year of questionnaire cycle (continuous), smoking in pack-years (never, 0.1-4.9, 5-19.9, 20-39.9, or $\geq 40$ ), history of diabetes (yes/no), body mass index $\left(<25,25-29.9,30-34.9\right.$, or $\left.\geq 35 \mathrm{~kg} / \mathrm{m}^{2}\right)$, physical activity (metabolic equivalent of task-hours/week in quintiles), alcohol intake $(0$, $0.1-4.9,5-14.9,15-29.9$, or $\geq 30 \mathrm{~g} /$ day), and regular multivitamin use (yes/no). We further adjusted for religious heritage (AJ or others). These covariates were treated as time-dependent to account for changes over time, if applicable. To reduce intraindividual variation and to consider long-term influences, we used the cumulative average for relevant covariates, which was the mean of all available data prior to each questionnaire cycle. The assumption of proportional hazards for the exposure variables and covariates was verified using Schoenfeld residual plots, which supported the proportionality of hazards during the follow-up period (data not shown). We assessed statistical interaction by entering main effect terms and the cross-product of family history of cancer and a stratification variable into the model and evaluating the Wald test. In all analyses, 2 -sided $P$ values $<0.05$ were considered statistically significant, and SAS statistical software (version 9.4, SAS Institute, Cary, NC, USA) was used.

\section{RESULTS}

During follow-up of 49,410 study participants $(1,173,906$ personyears), 452 men developed incident pancreatic adenocarcinoma. Table 1 summarises age-standardised baseline characteristics of participants, overall and by AJ ancestry. Supplementary Table S1 shows the distribution of family history of cancer by AJ ancestry. Compared with non-AJ men, AJ men were more likely to have

Table 1. Age-standardised characteristics of participants in the Health Professionals Follow-up Study, at baseline (1986) and by Ashkenazi Jewish ancestry (1998)

\begin{tabular}{|c|c|c|c|}
\hline \multirow[t]{2}{*}{ Characteristic $^{a}$} & \multirow[t]{2}{*}{ Baseline } & \multicolumn{2}{|c|}{ Ashkenazi Jewish ${ }^{\mathrm{b}}$} \\
\hline & & No & Yes \\
\hline No. of participants & 49,410 & 29,985 & 5580 \\
\hline Age, years & $54.5(9.8)$ & $65.0(9.1)$ & $67.0(9.9)$ \\
\hline \multicolumn{4}{|l|}{ Race } \\
\hline White & $90.7 \%$ & $91.6 \%$ & $90.8 \%$ \\
\hline Black & $1.0 \%$ & $0.8 \%$ & $0 \%$ \\
\hline Other & $3.3 \%$ & $2.7 \%$ & $3.8 \%$ \\
\hline Unknown & $5.0 \%$ & $4.8 \%$ & $5.4 \%$ \\
\hline Body mass index, $\mathrm{kg} / \mathrm{m}^{2}$ & $25.5(3.4)$ & $25.8(3.3)$ & $25.4(3.0)$ \\
\hline \multicolumn{4}{|l|}{ Smoking status } \\
\hline Current smoker & $10.0 \%$ & $5.3 \%$ & $2.5 \%$ \\
\hline Pack-years in ever smokers & $13.4(19.0)$ & $12.8(18.8)$ & $11.5(17.0)$ \\
\hline History of diabetes & $3.2 \%$ & $7.4 \%$ & $7.7 \%$ \\
\hline Physical activity, MET-hours/week & $18.8(26.3)$ & $27.7(21.7)$ & $26.5(21.3)$ \\
\hline Alcohol intake, g/day & $11.3(15.4)$ & $11.6(13.6)$ & $6.9(8.6)$ \\
\hline Regular multivitamin use & $41.7 \%$ & $59.1 \%$ & $58.8 \%$ \\
\hline \multicolumn{4}{|c|}{$\begin{array}{l}\text { MET Metabolic equivalent of task } \\
\text { a All variables other than age were standardised to age distribution of the } \\
\text { study population. Mean (standard deviation) was presented for continuous } \\
\text { variables } \\
\text { beligious heritage was assessed in } 1998 \text { and was reported by } 72.0 \% \text { of } \\
\text { participants from the baseline population in } 1986\end{array}$} \\
\hline
\end{tabular}




\begin{tabular}{|c|c|c|c|c|}
\hline \multirow{2}{*}{$\begin{array}{l}\text { Family } \\
\text { history }\end{array}$} & \multirow{2}{*}{$\begin{array}{l}\text { No. of } \\
\text { cases }\end{array}$} & \multirow{2}{*}{$\begin{array}{l}\text { Person- } \\
\text { years }\end{array}$} & \multicolumn{2}{|c|}{ HR for pancreatic cancer $(95 \% \mathrm{Cl})$} \\
\hline & & & Age-adjusted & $\begin{array}{l}\text { Multivariable- } \\
\text { adjusted }^{\mathrm{a}}\end{array}$ \\
\hline \multicolumn{5}{|c|}{ Breast cancer } \\
\hline Absent & 195 & 435,771 & 1 (referent) & 1 (referent) \\
\hline Present & 46 & 76,038 & $1.37(0.99-1.90)$ & $1.40(1.01-1.94)$ \\
\hline \multicolumn{5}{|c|}{ Colorectal cancer } \\
\hline Absent & 372 & $1,021,094$ & 1 (referent) & 1 (referent) \\
\hline Present & 80 & 152,732 & $1.20(0.94-1.54)$ & $1.21(0.95-1.55)$ \\
\hline \multicolumn{5}{|c|}{ Pancreatic cancer } \\
\hline Absent & 55 & 145,931 & 1 (referent) & 1 (referent) \\
\hline Present & 8 & 7529 & $2.49(1.17-5.33)$ & $2.79(1.28-6.07)$ \\
\hline \multicolumn{5}{|l|}{ Melanoma } \\
\hline Absent & 283 & 646,495 & 1 (referent) & 1 (referent) \\
\hline Present & 12 & 30,435 & $0.91(0.51-1.62)$ & $0.90(0.50-1.60)$ \\
\hline \multicolumn{5}{|c|}{ Prostate cancer } \\
\hline Absent & 285 & 665,289 & 1 (referent) & 1 (referent) \\
\hline Present & 55 & 114,591 & $1.10(0.82-1.47)$ & $1.10(0.82-1.48)$ \\
\hline \multicolumn{5}{|c|}{ Lung cancer } \\
\hline Absent & 197 & 457,620 & 1 (referent) & 1 (referent) \\
\hline Present & 29 & 55,818 & $1.12(0.75-1.68)$ & $1.15(0.77-1.72)$ \\
\hline \multicolumn{5}{|c|}{$\begin{array}{l}\text { CI Confidence interval, HR hazard ratio, MET metabolic equivalent of task } \\
\text { aThe Cox proportional hazards regression models were adjusted for age } \\
\text { (continuous), race (white, black, other, or unknown), calendar year of } \\
\text { questionnaire cycle (continuous), smoking in pack-years (never, } 0.1-4.9 \text {, } \\
5-19.9,20-39.9, \text { or } \geq 40), \text { history of diabetes (yes/no), body mass index }(<25 \text {, } \\
\left.25-29.9,30-34.9 \text {, or } \geq 35 \mathrm{~kg} / \mathrm{m}^{2}\right) \text {, physical activity (MET-hours } / \text { week in } \\
\text { quintiles), alcohol intake }(0,0.1-4.9,5-14.9,15-29.9, \text { or } \geq 30 \mathrm{~g} / \text { day), and } \\
\text { regular multivitamin use (yes } / \mathrm{no} \text { ) }\end{array}$} \\
\hline
\end{tabular}

family members with colorectal, breast, or pancreatic cancer, and were less likely to have those with prostate cancer. Compared to non-AJ individuals, $\mathrm{AJ}$ individuals appeared to be at a higher risk of pancreatic cancer, but the association did not reach statistical significance (multivariable-adjusted HR, 1.29; 95\% Cl, 0.94-1.77).

Family history of breast cancer was associated with higher risk of pancreatic cancer (HR, 1.40; 95\% Cl, 1.01-1.94; Table 2). There was a trend towards higher risk of pancreatic cancer in relation to family history of colorectal cancer $(\mathrm{HR}, 1.21 ; 95 \% \mathrm{Cl}, 0.95-1.55$; Table 2). When further adjusted for AJ ancestry, these associations remained largely unchanged $(\mathrm{HR}, 1.50[95 \% \mathrm{Cl}, 1.07-2.12]$ for breast cancer; and HR, 1.27 [95\% Cl, 0.93-1.73] for colorectal cancer; Table 3). As expected, family history of pancreatic cancer was associated with higher risk of the disease $(\mathrm{HR}, 2.79 ; 95 \% \mathrm{Cl}$, 1.28-6.07; Table 2). We observed no statistically significant association of family history of prostate cancer, melanoma, or lung cancer with pancreatic cancer risk $(P>0.49$, Table 2$)$.

We examined the association of family history of breast or colorectal cancer with pancreatic cancer risk in strata of AJ ancestry (Table 4). Family history of breast cancer was more strongly associated with pancreatic cancer risk in AJ individuals than in non-AJ Jewish individuals $\left(P_{\text {interaction }}=0.04\right)$. A similar differential association was observed for colorectal cancer, but the test for interaction was not statistically significant $\left(P_{\text {interaction }}=\right.$ 0.13). Compared with AJ individuals with no family history, those with a family history of breast and colorectal cancer had HRs of 2.61 (95\% Cl, 1.41-4.82) and 1.92 (95\% Cl, 1.05-3.49), respectively. The association of family history of colorectal cancer with pancreatic cancer risk appeared to be stronger for never smokers than forever smokers. We observed no statistically significant
Table 3. Risk of incident pancreatic cancer by family history of cancer with adjustment for Ashkenazi Jewish ancestry

\begin{tabular}{|c|c|c|c|c|}
\hline \multirow{2}{*}{$\begin{array}{l}\text { Family } \\
\text { history }\end{array}$} & \multirow{2}{*}{$\begin{array}{l}\text { No. of } \\
\text { cases }\end{array}$} & \multirow{2}{*}{$\begin{array}{l}\text { Person- } \\
\text { years }\end{array}$} & \multicolumn{2}{|c|}{ HR for pancreatic cancer $(95 \% \mathrm{Cl})$} \\
\hline & & & Age-adjusted & $\begin{array}{l}\text { Multivariable- } \\
\text { adjusted }^{a}\end{array}$ \\
\hline \multicolumn{5}{|c|}{ Breast cancer } \\
\hline Absent & 167 & 331,775 & 1 (referent) & 1 (referent) \\
\hline Present & 43 & 57,475 & $1.49(1.06-2.10)$ & $1.50(1.07-2.12)$ \\
\hline \multicolumn{5}{|c|}{ Colorectal cancer } \\
\hline Absent & 207 & 417,949 & 1 (referent) & 1 (referent) \\
\hline Present & 52 & 72,484 & $1.28(0.94-1.74)$ & $1.27(0.93-1.73)$ \\
\hline \multicolumn{5}{|c|}{ Pancreatic cancer } \\
\hline Absent & 52 & 109,930 & 1 (referent) & 1 (referent) \\
\hline Present & 8 & 5681 & $2.76(1.29-5.93)$ & $3.05(1.39-6.69)$ \\
\hline \multicolumn{5}{|l|}{ Melanoma } \\
\hline Absent & 189 & 354,438 & 1 (referent) & 1 (referent) \\
\hline Present & 9 & 17,796 & $0.97(0.49-1.90)$ & $0.96(0.49-1.90)$ \\
\hline \multicolumn{5}{|c|}{ Prostate cancer } \\
\hline Absent & 201 & 381,247 & 1 (referent) & 1 (referent) \\
\hline Present & 37 & 68,343 & $1.01(0.71-1.44)$ & $1.03(0.72-1.47)$ \\
\hline \multicolumn{5}{|c|}{ Lung cancer } \\
\hline Absent & 138 & 267,933 & 1 (referent) & 1 (referent) \\
\hline Present & 20 & 32,726 & $1.11(0.69-1.80)$ & $1.14(0.70-1.85)$ \\
\hline \multicolumn{5}{|c|}{$\begin{array}{l}\text { CI Confidence interval, HR hazard ratio, MET metabolic equivalent of task } \\
\text { aThe Cox proportional hazards regression models were adjusted for age } \\
\text { (continuous), race (white, black, other, or unknown), calendar year of } \\
\text { questionnaire cycle (continuous), smoking in pack-years (never, } 0.1-4.9 \text {, } \\
5-19.9,20-39.9, \text { or } \geq 40), \text { history of diabetes (yes } / \text { no), body mass index }(<25 \text {, } \\
25-29.9,30-34.9 \text {, or } \geq 35 \mathrm{~kg} / \mathrm{m}^{2} \text { ), physical activity (MET-hours/week in } \\
\text { quintiles), alcohol intake }(0,0.1-4.9,5-14.9,15-29.9 \text {, or } \geq 30 \mathrm{~g} / \text { day), regular } \\
\text { multivitamin use (yes } / \mathrm{no} \text { ), and AJ ancestry (yes } / \mathrm{no} \text { ) }\end{array}$} \\
\hline
\end{tabular}

effect modification for the association of family history of breast or colorectal cancer with pancreatic cancer risk by BMI or DM status $\left(P_{\text {interaction }}>0.60\right.$, Table 5). Nevertheless, those participants with a history of diabetes mellitus and a family history of breast or colorectal cancer had notably higher risks of pancreatic cancer compared to participants with no diabetes and family history (HR, 3.09 [95\% Cl, 1.60-5.98] for breast cancer; and $\mathrm{HR}, 2.44[95 \% \mathrm{Cl}$, $1.45-4.09]$ for colorectal cancer).

\section{DISCUSSION}

Within a large U.S. cohort with 30 years of follow-up, we prospectively examined the association of family history of cancer with risk of incident pancreatic cancer. In addition, we examined how the association differed according to religious heritage and major risk factors for pancreatic cancer. Specifically, we evaluated family history of melanoma and breast, colorectal, lung, pancreatic, or prostate cancer. Notably, family history of breast cancer was associated with approximately $40 \%$ higher risk of developing pancreatic cancer over the study follow-up period. Interestingly, the elevated risk with a family history of breast or colorectal cancer was largely confined to individuals of AJ descent, identifying a group of participants at particularly elevated risk of pancreatic cancer. Furthermore, in stratified analyses, participants with both diabetes mellitus and a family history of breast or colorectal cancer had a greater than 2 -fold risk of developing pancreatic cancer. Similar to data from previous studies, ${ }^{3-8}$ we noted a 2.8-fold increase in risk for pancreatic cancer with a family history of this malignancy. These findings indicate the potential of 
Table 4. Risk of incident pancreatic cancer by family history of breast or colorectal cancer, stratified by Ashkenazi Jewish ancestry

\begin{tabular}{|c|c|c|c|c|c|c|}
\hline & \multicolumn{2}{|c|}{ Family history of breast cancer } & $P_{\text {interaction }}{ }^{\mathrm{b}}$ & \multicolumn{2}{|c|}{ Family history of colorectal cancer } & $P_{\text {interaction }}$ \\
\hline Ashkenazi Jewish & & & & & & \\
\hline No. of cases & 30 & 15 & & 36 & 17 & \\
\hline Person-years & 50,651 & 10,172 & & 62,891 & 13,042 & \\
\hline Age-adjusted HR $(95 \% \mathrm{Cl})$ & 1 (referent) & $2.57(1.40-4.73)$ & 0.04 & 1 (referent) & $1.92(1.06-3.49)$ & 0.12 \\
\hline No. of cases & 137 & 28 & & 171 & 35 & \\
\hline Person-years & 281,124 & 47,303 & & 355,058 & 59,442 & \\
\hline Age-adjusted HR (95\% Cl) & 1 (referent) & $1.22(0.81-1.82)$ & & 1 (referent) & $1.10(0.76-1.59)$ & \\
\hline Multivariable HR $(95 \% \mathrm{Cl})^{\mathrm{a}}$ & 1 (referent) & $1.22(0.82-1.83)$ & & 1 (referent) & $1.11(0.77-1.60)$ & \\
\hline
\end{tabular}

family history to identify individuals at elevated risk for pancreatic cancer, particularly when combined with additional factors such as AJ ancestry and a history of diabetes mellitus.

In a meta-analysis of 8 case-control studies and 1 prospective cohort study involving 6568 pancreatic cancer cases, the pooled relative risk for pancreatic cancer comparing positive vs. negative family history of this malignancy was 1.80 (95\% Cl, 1.48-2.12). ${ }^{40}$ Although increased risk of pancreatic cancer has been also reported among individuals with a family history of other cancer types, data from prospective studies are limited with inconsistent conclusions. In a prospective study of a U.S.-based cohort, family history of breast and colorectal cancer was associated with modestly increased pancreatic cancer mortality with HRs of 1.06 (95\% Cl, 0.97-1.15) and $1.12(95 \% \mathrm{Cl}, 1.01-1.23)$, respectively. ${ }^{8}$ Data from a large cancer registry in Sweden suggested no significant increase in pancreatic cancer incidence associated with positive family history of breast, colon, and rectal cancer with standardised incidence ratios (SIRs) of $0.99(95 \% \mathrm{Cl}$, 0.75-1.27), $0.91(95 \% \mathrm{Cl}, 0.66-1.24)$, and $1.34(95 \% \mathrm{Cl}$, 0.94-1.87), respectively. ${ }^{5}$ In a nested case-control study pooling 12 prospective cohort studies and a case-control study, family history of breast and colorectal cancer was not statistically significantly associated with pancreatic cancer risk (odds ratios, 1.21 [95\% Cl, 0.97-1.51] and 1.17 [95\% Cl, 0.93-1.47], respectively). ${ }^{6}$

Shared genetic architecture may contribute to familial predisposition to multiple cancer types. For pancreatic cancer, these alterations may include germline high penetrance mutations in the DNA double-strand break repair genes responsible for inherited breast and ovarian cancer (e.g., BRCA1, BRCA2, and $P A L B 2)$ and the DNA mismatch repair genes responsible for Lynch syndrome (e.g., MLH1, MSH2, MSH6, and PMS2). ${ }^{18-20,41-43}$ The Breast Cancer Linkage Consortium reported the relative risk for pancreatic cancer of $2.26(95 \% \mathrm{Cl}, 1.26-4.06)$ for $B R C A 1$ mutation carriers and $3.51(95 \% \mathrm{Cl}, 1.87-6.58)$ for BRCA2 mutation carriers. $^{16,17}$ A prospective study reported a SIR for pancreatic cancer of $10.68(95 \% \mathrm{Cl}, 2.68-47.70)$ among 446 carriers of a mismatch repair gene mutation. ${ }^{20}$ The aggregate of multiple low penetrance single nucleotide variants may also contribute to shared risk of multiple malignancies. ${ }^{44}$

Few prospective studies have evaluated the association of family history with risk of pancreatic cancer after considering religious heritage. In the current study, family history of breast and colorectal cancer appeared to be more strongly associated with risk of pancreatic cancer in AJ men than in non-AJ men. AJ individuals are at higher risk of several cancer types including pancreatic cancer. ${ }^{31-34}$ Ashkenazi Jews are known to have founder mutations in BRCA1 (185_186delAG and 5382insC reported in $0.4 \%$ and $0.1 \%$, respectively, of Ashkenazi women) $)^{28}$ and BRCA2 (6174delT reported in $0.6 \%$ Ashkenazi women) ${ }^{28}$ underlying hereditary breast cancer. ${ }^{28,29}$ They also have founder mutations in MSH2 (1906G $>$ C reported in $0.44 \%$ Ashkenazi Jews with colorectal cancer) ${ }^{45}$ and MSH6 (3959_3962delCAAG and 3984_3987dupGTCA reported in $0.11 \%$ and $0.30 \%$, respectively, of Ashkenazi Jews with colorectal cancer) ${ }^{46}$ underlying Lynch syndrome. ${ }^{30}$ Those founder mutations may contribute to predisposition to pancreatic cancer. Therefore, family history of breast cancer in $A J$ men may be a surrogate for founder mutations in $B R C A 1$ and BRCA2, whereas family history of colorectal cancer potentially serves as a surrogate for founder mutations in $\mathrm{MSH} 2$ and MSH6. Taken together, family history of breast or colorectal cancer in Ashkenazi Jews may mark a population with high risk of pancreatic cancer mediated through genetic alterations in these genes or others. Considering the joint risk estimates associated with a family history of breast or colorectal cancer, AJ ancestry, and diabetes status may assist in defining high-risk populations for disease screening.

Our study has notable strengths, including a prospective study design, large sample size with over 400 pancreatic cancer cases, and availability of religious heritage data. The data on family history and covariates were collected prospectively and updated repeatedly, which allowed us to rigorously adjust for potential confounders, to evaluate effect modification by other risk factors, and more importantly, to assess cancer family history without substantial recall bias, which can be a major problem when analysing family history data after a cancer diagnosis. ${ }^{47,48}$

The current study also has limitations that should be considered, including the availability of family history data for a select set of malignancies and self-reported information on family history. Nonetheless, misclassifications of family history status would likely have biased our findings towards the null hypothesis, as all participants were asked their family history prior to a diagnosis of pancreatic cancer. Though we cannot rule out the possibility of unmeasured confounding, our multivariable models included known and potential confounders associated with pancreatic cancer risk, ${ }^{2,39}$ and our findings did not differ 
Family history of cancer, Ashkenazi Jewish ancestry, and pancreatic...

T Hamada et al.

Table 5. Risk of incident pancreatic cancer by family history of breast or colorectal cancer, stratified by covariates

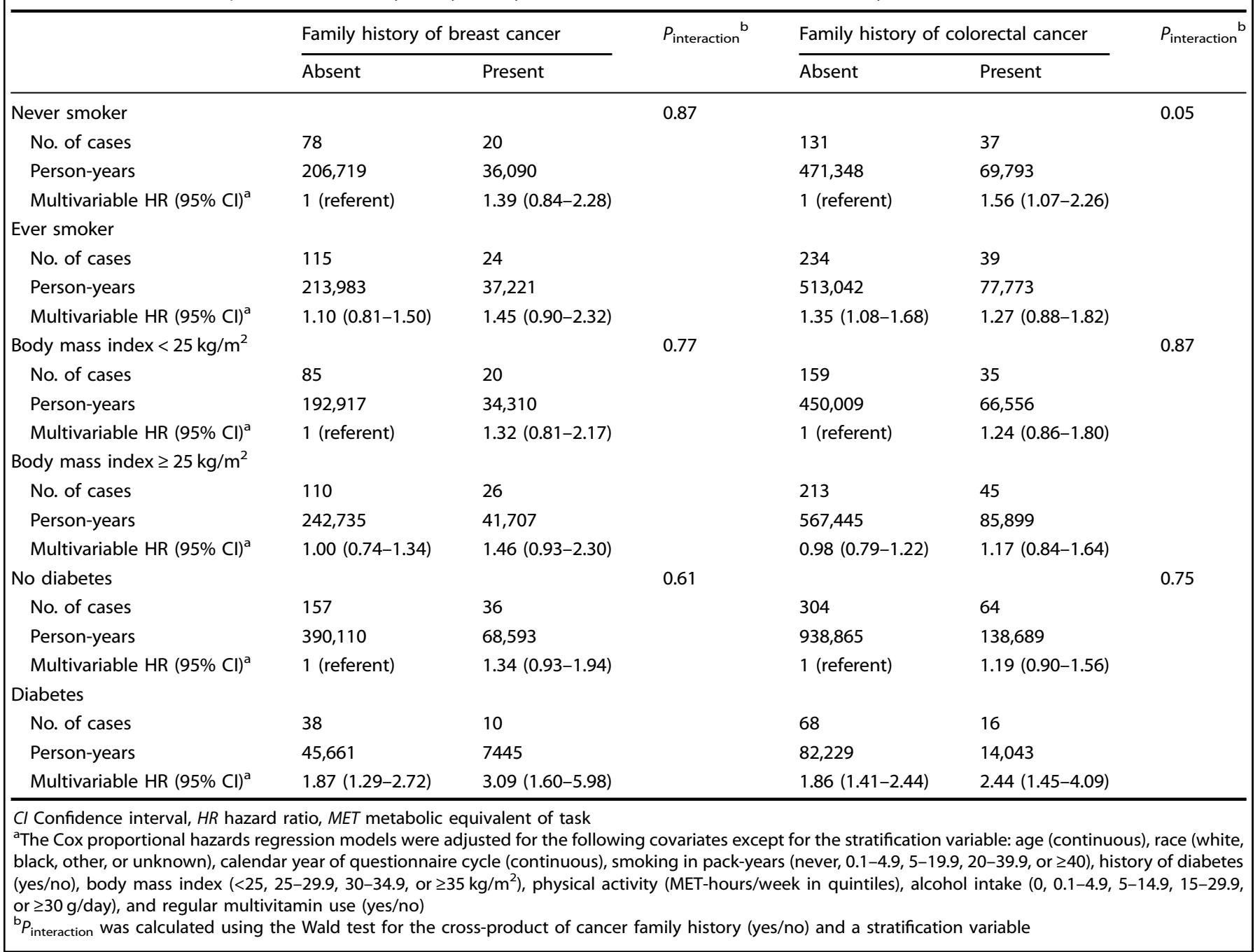

substantially between age-adjusted and multivariable-adjusted models. We investigated family history of several cancer types, such that false positive results from multiple hypothesis testing are a possibility. However, strong a priori hypotheses are present for family history of breast and colorectal cancer, given the known founder mutations related to these cancer types in individuals of AJ descent. Finally, all participants were males in the current study, and therefore, our findings should be validated in female populations.

In conclusion, family history of breast cancer in one or more first-degree relatives was associated with increased incidence of pancreatic cancer in a large prospective cohort study of U.S. men. Individuals with a family history of colorectal cancer appeared to carry a modestly increased risk of pancreatic cancer. These associations were more pronounced among individuals of $\mathrm{AJ}$ descent and with a history of diabetes mellitus. Therefore, family history of other malignancies may be relevant for determining pancreatic cancer risk, particularly when combined with known risk factors for this disease.

\section{ACKNOWLEDGEMENTS}

We would like to thank the participants and staff of the HPFS for their valuable contributions as well as the following state cancer registries for their help: $A L, A Z, A R$, $C A, C O, C T, D E, F L, G A, I D, I L, I N, I A, K Y, L A, M E, M D, M A, M I, N E, N H, N J, N Y, N C, N D$,
$\mathrm{OH}, \mathrm{OK}, \mathrm{OR}, \mathrm{PA}, \mathrm{RI}, \mathrm{SC}, \mathrm{TN}, \mathrm{TX}, \mathrm{VA}, \mathrm{WA}, \mathrm{WY}$. We assume full responsibility for analyses and interpretation of the data. The HPFS is supported by U.S. National Institutes of Health (NIH) grants (UM1 CA167552 and U01 CA167552). This work was additionally supported by NIH R01 CA205406 and the Broman Fund for Pancreatic Cancer Research to K.N.; by NIH R01 CA124908 and P50 CA127003, the Robert T. and Judith B. Hale Fund for Pancreatic Cancer, Perry S. Levy Fund for Gastrointestinal Cancer Research, and Pappas Family Research Fund for Pancreatic Cancer to C.S.F.; by NIH R35 CA197735 to S.O.; and by Hale Center for Pancreatic Cancer Research, NIH/ National Cancer Institute (NCl) U01 CA210171, Department of Defense CA130288, Lustgarten Foundation, Stand Up to Cancer, Pancreatic Cancer Action Network, Noble Effort Fund, Wexler Family Fund, and Promises for Purple to B.M.W. The content is solely the responsibility of the authors and does not necessarily represent the official views of NIH. The funders had no role in study design, data collection and analysis, decision to publish, or preparation of the manuscript.

\section{AUTHOR CONTRIBUTIONS}

T.H., C.Y., and B.M.W. drafted the manuscript. T.H., C.Y., N.K., V.M.O., A.B., C.S.F., S.O., and B.M.W. planned and conducted the study. All authors collected, analysed, and interpreted the data. M.B.Y., K.P., N.K., V.M.O., A.B., J.A.N., D.A.R., M.G., K.N., P.K., M.J.S., E.L.G., C.S.F., S.O., and B.M.W. edited the manuscript. C.S.F., S.O., and B.M.W. supervised the study. All authors approved the final submitted draft.

\section{ADDITIONAL INFORMATION}

Supplementary information is available for this paper at https://doi.org/10.1038/ s41416-019-0426-5. 
Competing interests: C.S.F. declares consulting for Agios Inc., Bain Capital L.P., Bayer A.G., Celgene Inc., Dicerna Inc., Eli Lilly, Entrinsic Health Solutions Inc., Five Prime Therapeutics Inc., Genentech Inc., Gilead Sciences Inc., KEW Inc., Merck Inc., Merrimack Pharmaceuticals Inc., Pfizer Inc., Sanofi Inc., Taiho Ltd., and Unum Therapeutics Inc. He also serves as a director for CytomX Therapeutics Inc. and owns unexercised stock options for CytomX Therapeutics Inc. and Entrinsic Health Solutions Inc. B.M.W. declares research funding from Celgene Inc., and consulting for BioLineRx Ltd., G1 Therapeutics Inc., and GRAIL Inc. The remaining authors declare no competing interests.

Data availability: The datasets used and/or analysed during the current study are available from the corresponding author on reasonable request.

Ethics approval and consent to participate: Informed consent was obtained from all participants at study enrolment, and the HPFS was approved by the institutional review board at Harvard T.H. Chan School of Public Health (Boston, MA, USA). The study was conducted in accordance with the Declaration of Helsinki.

Note: This work is published under the standard license to publish agreement. After 12 months the work will become freely available and the license terms will switch to a Creative Commons Attribution 4.0 International (CC BY 4.0).

Publisher's note: Springer Nature remains neutral with regard to jurisdictional claims in published maps and institutional affiliations.

\section{REFERENCES}

1. Siegel, R. L., Miller, K. D. \& Jemal, A. Cancer statistics, 2019. CA Cancer J. Clin. 69, 7-34 (2019).

2. Kleeff, J., Korc, M., Apte, M., La Vecchia, C., Johnson, C. D. \& Biankin, A. V. et al. Pancreatic cancer. Nat. Rev. Dis. Prim. 2, 16022 (2016).

3. Brune, K. A., Lau, B., Palmisano, E., Canto, M., Goggins, M. G. \& Hruban, R. H. et al. Importance of age of onset in pancreatic cancer kindreds. J. Natl. Cancer Inst. 102, 119-126 (2010).

4. Coughlin, S. S., Calle, E. E., Patel, A. V. \& Thun, M. J. Predictors of pancreatic cancer mortality among a large cohort of United States adults. Cancer Causes Control 11, 915-923 (2000).

5. Hemminki, K. \& Li, X. Familial and second primary pancreatic cancers: a nationwide epidemiologic study from Sweden. Int. J. Cancer 103, 525-530 (2003).

6. Jacobs, E. J., Chanock, S. J., Fuchs, C. S., Lacroix, A., McWilliams, R. R. \& Steplowski, E. et al. Family history of cancer and risk of pancreatic cancer: a pooled analysis from the Pancreatic Cancer Cohort Consortium (PanScan). Int. J. Cancer 127, 1421-1428 (2010).

7. Schulte, A., Pandeya, N., Fawcett, J., Fritschi, L., Klein, K. \& Risch, H. A. et al. Association between family cancer history and risk of pancreatic cancer. Cancer Epidemiol. 45, 145-150 (2016).

8. Jacobs, E. J., Rodriguez, C., Newton, C. C., Bain, E. B., Patel, A. V. \& Feigelson, H. S. et al. Family history of various cancers and pancreatic cancer mortality in a large cohort. Cancer Causes Control 20, 1261-1269 (2009).

9. Wang, L., Brune, K. A., Visvanathan, K., Laheru, D., Herman, J. \& Wolfgang, C. et al. Elevated cancer mortality in the relatives of patients with pancreatic cancer. Cancer Epidemiol. Biomark. Prev. 18, 2829-2834 (2009).

10. McWilliams, R. R., Rabe, K. G., Olswold, C., De Andrade, M. \& Petersen, G. M. Risk of malignancy in first-degree relatives of patients with pancreatic carcinoma. Cancer 104, 388-394 (2005).

11. Antwi, S. O., Fagan, S. E., Chaffee, K. G., Bamlet, W. R., Hu, C., \& Polley, E. C. et al. Risk of different cancers among first-degree relatives of pancreatic cancer patients: influence of probands' susceptibility gene mutation status. J. Nat/ Cancer Inst. (2018).

12. Zhen, D. B., Rabe, K. G., Gallinger, S., Syngal, S., Schwartz, A. G. \& Goggins, M. G. et al. BRCA1, BRCA2, PALB2, and CDKN2A mutations in familial pancreatic cancer: a PACGENE study. Genet. Med. 17, 569-577 (2015).

13. Jones, S., Hruban, R. H., Kamiyama, M., Borges, M., Zhang, X. \& Parsons, D. W. et al. Exomic sequencing identifies PALB2 as a pancreatic cancer susceptibility gene. Science 324, 217 (2009).

14. Petersen, G. M. Familial pancreatic adenocarcinoma. Hematol. Oncol. Clin. North. Am. 29, 641-653 (2015).

15. Roberts, N. J., Norris, A. L., Petersen, G. M., Bondy, M. L., Brand, R. \& Gallinger, S. et al. Whole genome sequencing defines the genetic heterogeneity of familial pancreatic cancer. Cancer Discov. 6, 166-175 (2016).

16. Breast Cancer Linkage Consortium. Cancer risks in BRCA2 mutation carriers. J. Natl Cancer Inst. 91, 1310-1316 (1999).
17. Thompson, D. \& Easton, D. F. Cancer Incidence in BRCA1 mutation carriers. J. Nat/ Cancer Inst. 94, 1358-1365 (2002).

18. Klein, A. P. Genetic susceptibility to pancreatic cancer. Mol. Carcinog. 51, 14-24 (2012).

19. Syngal, S., Brand, R. E., Church, J. M., Giardiello, F. M., Hampel, H. L. \& Burt, R. W. ACG clinical guideline: Genetic testing and management of hereditary gastrointestinal cancer syndromes. Am. J. Gastroenterol. 110, 223-262 (2015).

20. Win, A. K., Young, J. P., Lindor, N. M., Tucker, K. M., Ahnen, D. J. \& Young, G. P. et al. Colorectal and other cancer risks for carriers and noncarriers from families with a DNA mismatch repair gene mutation: a prospective cohort study. J. Clin. Oncol. 30, 958-964 (2012)

21. Matsubayashi, H., Takaori, K., Morizane, C., Maguchi, H., Mizuma, M. \& Takahashi, $\mathrm{H}$. et al. Familial pancreatic cancer: Concept, management and issues. World $\mathrm{J}$. Gastroenterol. 23, 935-948 (2017).

22. Mocci, E., Milne, R. L., Mendez-Villamil, E. Y., Hopper, J. L., John, E. M. \& Andrulis, I. L. et al. Risk of pancreatic cancer in breast cancer families from the breast cancer family registry. Cancer Epidemiol. Biomark. Prev. 22, 803-811 (2013).

23. Borg, A., Sandberg, T., Nilsson, K., Johannsson, O., Klinker, M. \& Masback, A. et al. High frequency of multiple melanomas and breast and pancreas carcinomas in CDKN2A mutation-positive melanoma families. J. Natl Cancer Inst. 92, 1260-1266 (2000).

24. Carmi, S., Hui, K. Y., Kochav, E., Liu, X., Xue, J. \& Grady, F. et al. Sequencing an Ashkenazi reference panel supports population-targeted personal genomics and illuminates Jewish and European origins. Nat. Commun. 5, 4835 (2014).

25. Behar, D. M., Yunusbayev, B., Metspalu, M., Metspalu, E., Rosset, S. \& Parik, J. et al. The genome-wide structure of the Jewish people. Nature 466, 238-242 (2010).

26. Bray, S. M., Mulle, J. G., Dodd, A. F., Pulver, A. E., Wooding, S. \& Warren, S. T. Signatures of founder effects, admixture, and selection in the Ashkenazi Jewish population. Proc. Natl Acad. Sci. USA 107, 16222-16227 (2010).

27. Stadler, Z. K., Salo-Mullen, E., Patil, S. M., Pietanza, M. C., Vijai, J. \& Saloustros, E. et al. Prevalence of BRCA1 and BRCA2 mutations in Ashkenazi Jewish families with breast and pancreatic cancer. Cancer 118, 493-499 (2012).

28. Metcalfe, K. A., Poll, A., Royer, R., Llacuachaqui, M., Tulman, A. \& Sun, P. et al. Screening for founder mutations in BRCA1 and BRCA2 in unselected Jewish women. J. Clin. Oncol. 28, 387-391 (2010).

29. Abeliovich, D., Kaduri, L., Lerer, I., Weinberg, N., Amir, G. \& Sagi, M. et al. The founder mutations 185delAG and 5382insC in BRCA1 and 6174delT in BRCA2 appear in $60 \%$ of ovarian cancer and $30 \%$ of early-onset breast cancer patients among Ashkenazi women. Am. J. Hum. Genet. 60, 505-514 (1997).

30. Ponti, G., Castellsague, E., Ruini, C., Percesepe, A. \& Tomasi, A. Mismatch repair genes founder mutations and cancer susceptibility in Lynch syndrome. Clin. Genet. 87, 507-516 (2015).

31. Eldridge, R. C., Gapstur, S. M., Newton, C. C., Goodman, M., Patel, A. V. \& Jacobs, E. J. Jewish ethnicity and pancreatic cancer mortality in a large U.S. cohort. Cancer Epidemiol. Biomark. Prev. 20, 691-698 (2011).

32. Salo-Mullen, E. E., O'Reilly, E. M., Kelsen, D. P., Ashraf, A. M., Lowery, M. A. \& Yu, K. $\mathrm{H}$. et al. Identification of germline genetic mutations in patients with pancreatic cancer. Cancer 121, 4382-4388 (2015).

33. Lynch, H. T., Deters, C. A., Lynch, J. F. \& Brand, R. E. Familial pancreatic carcinoma in Jews. Fam. Cancer 3, 233-240 (2004).

34. Laitman, Y., Keinan Boker, L., Liphsitz, I., Weissglas-Volkov, D., Litz-Philipsborn, S. \& Schayek, H. et al. Cancer risks in Jewish male BRCA1 and BRCA2 mutation carriers. Breast Cancer Res. Treat. 150, 631-635 (2015).

35. Yeo, T. P. Demographics, epidemiology, and inheritance of pancreatic ductal adenocarcinoma. Semin. Oncol. 42, 8-18 (2015).

36. Tempero, M. A., Malafa, M. P., Al-Hawary, M., Asbun, H., Bain, A. \& Behrman, S. W. et al. Pancreatic adenocarcinoma, version 2.2017, NCCN clinical practice guidelines in oncology. J. Natl Compr. Canc. Netw. 15, 1028-1061 (2017).

37. Michaud, D. S., Liu, Y., Meyer, M., Giovannucci, E. \& Joshipura, K. Periodontal disease, tooth loss, and cancer risk in male health professionals: a prospective cohort study. Lancet Oncol. 9, 550-558 (2008).

38. Rich-Edwards, J. W., Corsano, K. A. \& Stampfer, M. J. Test of the national death index and equifax nationwide death search. Am. J. Epidemiol. 140, 1016-1019 (1994).

39. Kamisawa, T., Wood, L. D., Itoi, T. \& Takaori, K. Pancreatic cancer. Lancet $\mathbf{3 8 8}$, 73-85 (2016).

40. Permuth-Wey, J. \& Egan, K. M. Family history is a significant risk factor for pancreatic cancer: results from a systematic review and meta-analysis. Fam. Cancer $\mathbf{8}$, 109-117 (2009)

41. Kuchenbaecker, K. B., Hopper, J. L., Barnes, D. R., Phillips, K. A., Mooij, T. M. \& RoosBlom, M. J. et al. Risks of breast, ovarian, and contralateral breast cancer for BRCA1 and BRCA2 mutation carriers. JAMA 317, 2402-2416 (2017).

42. Grant, R. C., Selander, I., Connor, A. A., Selvarajah, S., Borgida, A. \& Briollais, L. et al. Prevalence of germline mutations in cancer predisposition genes in patients with pancreatic cancer. Gastroenterology 148, 556-564 (2015). 
Family history of cancer, Ashkenazi Jewish ancestry, and pancreatic...

T Hamada et al.

854

43. Underhill, M. L., Germansky, K. A. \& Yurgelun, M. B. Advances in hereditary colorectal and pancreatic cancers. Clin. Ther. 38, 1600-1621 (2016).

44. Lindstrom, S., Finucane, H., Bulik-Sullivan, B., Schumacher, F. R., Amos, C. I. \& Hung, R. J. et al. Quantifying the genetic correlation between multiple cancer types. Cancer Epidemiol. Biomark. Prev. 26, 1427-1435 (2017).

45. Foulkes, W. D., Thiffault, I., Gruber, S. B., Horwitz, M., Hamel, N. \& Lee, C. et al. The founder mutation MSH2*1906G-- $>C$ is an important cause of hereditary nonpolyposis colorectal cancer in the Ashkenazi Jewish population. Am. J. Hum. Genet. 71, 1395-1412 (2002).
46. Raskin, L., Schwenter, F., Freytsis, M., Tischkowitz, M., Wong, N. \& Chong, G. et al. Characterization of two Ashkenazi Jewish founder mutations in MSH6 gene causing Lynch syndrome. Clin. Genet. 79, 512-522 (2011).

47. Ziogas, A., Horick, N. K., Kinney, A. Y., Lowery, J. T., Domchek, S. M. \& Isaacs, C. et al. Clinically relevant changes in family history of cancer over time. JAMA 306, 172-178 (2011).

48. Acheson, L. S. Recording, interpreting, and updating the family history of cancer: implications for cancer prevention. JAMA 306, 208-210 (2011). 